\title{
Negative Assimilation: How Immigrants Experience Economic Mobility in Japan
}

\author{
Ayumi Takenaka \\ Bry Mawr College \\ Makiko Nakamuro \\ Tohoku University \\ Kenji Ishida \\ Tohoku University
}

This paper examines the economic mobility of foreign migrants in Japan. In a country that is largely regarded as homogeneous and closed to outsiders, how and to what extent do immigrants achieve economic success? A survey conducted by the authors revealed that the conventional assimilationist perspective does not fully explain immigrants' economic success in Japan. Migrants from the West experience what Chiswick and Miller (Industrial and Labor Relations Review 2011; 64: 502-525) refer to as "negative assimilation." That is, their earnings decline over time in Japan. While negative assimilation was not clearly observed among immigrants from neighboring Asian countries, wages among them did not increase with the length of their stay in Japan. For both groups, the skills they brought from abroad were found to be largely accountable for their economic success, while locally specific human capital, such as education acquired in the host society, did not contribute to their earnings.

\section{INTRODUCTION}

Classic assimilation thesis regards time spent in the host society as a crucial factor for immigrants' assimilation and upward social mobility. Underlying the notion is the assumption that skills and cultural knowledge acquired over time in the host society contribute to higher income and higher-status occupations. Although the relationship between the 
acquisition of host culture (known largely as acculturation or assimilation) and social mobility is often conflated, this relationship needs to be examined carefully (Gans, 2007). While immigrants typically move up the socioeconomic ladder over time as they acquire culture and skills relevant for the host society, some indeed experience what Chiswick and Miller (2011, 2012) call "negative assimilation." In contrast to conventional views of assimilation and immigrants' mobility, Chiswick and Miller (2011, 2012) found that some immigrants' earnings decline, as they prolong their stay in, and assimilate more readily to, the host society. They observed this trend where immigrants came from countries similar to the host society in terms of culture, labor market practices, and economic standing, such as immigrants from the UK to the U.S. In a similar vein, Massey and Sanchez (2012) found that Latin American immigrants and their descendants in the U.S. tend to develop a stronger identity as "Latinos" in opposition to native "Americans," as they stay longer in the U.S. Rumbaut (1997) also found "negative assimilation" among some immigrants in that their health conditions deteriorate as they adopt more American diet and lifestyle over time.

How and under what conditions do immigrants experience "negative assimilation"? More broadly, how do acculturation and assimilation relate to social mobility? The objective of this paper was to examine these questions by focusing on the economic outcome of assimilation and acculturation in Japan where the number of immigrants has steadily increased in recent decades. Specifically, we examine the effects of time spent and education acquired in Japan on immigrants' economic attainment.

Negative assimilation is particularly plausible in countries, such as Japan, for two reasons. First, Japan admits only skilled migrants, at least in principle, as stipulated by the amendment of the Immigration Control and Refugee Recognition Act of 1989. ${ }^{1}$ This condition is prone to produce negative assimilation, as skilled immigrants, who can expect favorable wage rewards at the time of entry, are more likely to see their wages decline than unskilled immigrants who tend to become incorporated into the bottom of the host labor market, at least initially. Second, the conventional assimilation model developed on the basis of South-to-North migration may not work the same in non-Western, non-traditional countries of

${ }^{1}$ Japan does not officially admit unskilled foreign migrants, although in reality it has admitted foreigners, such as South Americans of Japanese descent, who mostly engage in manual labor. Those migrants are admitted based on family ties as Japanese descendants. 
immigration, like Japan, especially when migration originates in the West. As more and more countries around the world begin to receive immigrants by seeking to attract skilled migrants, Japan, provides a crucial test case to re-evaluate the assimilation model prevalent in the Western context. It also helps advance our understanding of immigrant assimilation and integration in general, as immigration to non-Western countries is relatively understudied, at least in English-language scholarship.

The questions of how immigrants "make it" or fail to "make it" in Japan are important in themselves where the number of immigrants ${ }^{2}$ is expected to increase in the future. Currently at 2 million or just 1.7 percent of the total population (Ministry of Justice, 2014), the number has nonetheless grown since 1989. Most of those "newcomers" are labor migrants who entered as "skilled" migrants under the new immigration policy of 1989, although many other migrants, especially South Americans of Japanese descent, also entered to engage in unskilled labor, mostly in manufacturing. In 2013, foreign laborers engaged in occupations, such as manufacturing (36.6\%), services $(11.5 \%)$, sales $(11.1 \%)$, and education (6.9\%) (Ministry of Health, Labour and Welfare, 2014). Although much research has pointed out the segmented nature of immigrant incorporation into the Japanese labor market, the pattern of incorporation depends much on immigrants' nationality and legal status (e.g., Kajita and Miyajima, 2002; Kajita, Tannno, and Higuchi, 2005). While most South American migrants, admitted under the special clause as Japanese descendants, are incorporated into the marginalized sector where they earn a fixed hourly wage regardless of their skills and education, professional workers admitted through the skilled migration channel are more likely to be incorporated into the core labor market (Takenoshita, 2006). It is unclear, however, to what extent, and how, those skilled migrants can "make it," once they were incorporated into the specific segments of the Japanese labor market.

The growing volume of foreign migration reflects Japan's policy to attract and retain global skills. In the context of population aging and prolonged economic recession, the government is enforcing the policy as a way to revitalize its economy and society (Tsukazaki, 2008; Council on Promotion of Human Resource for Globalization Development, 2011; Ministry of Justice, 2012). The "New Growth Strategy," implemented by

\footnotetext{
${ }^{2}$ The term "immigrant" refers here to foreign nationals officially registered in Japan as long-term residents. The Japanese government does not use the term "immigrant."
} 
the Cabinet Office in 2010, identifies the incorporation of foreign talent as a key policy goal. This has subsequently led to various measures, such as a point-based system, to further facilitate the entry and retention of skilled foreign migrants (Ministry of Justice, 2012).

Particularly crucial is a measure to attract foreign talent via education. Through initiatives, such as the "Plan to Accept 300,000 Foreign Students" (Ministry of Education, Culture, Sports and Technology, 2008) and the "Career Development Program for Foreign Students in Japan" (Ministry of Economy, Trade, and Industry, 2007), the government has placed a greater importance on student migration as a crucial strategy. Consequently, the number of foreign students has increased from 41,000 in 1990 to 140,000 in 2010 (JASSO, 2012), as has the number of those who stay to work in Japan after graduation by adjusting their visa status for instance, the number grew from 2,600 in 1997 to 11,000 in 2008 (Ministry of Justice, 2009).

Often referred to as "educationally channeled migration" (Ziguras and Law, 2006; Liu-Farrer, 2009) or "Japanese-bred talent cultivation scheme" (Sakanaka, 2011; LDP, 2008), international student mobility is regarded as an important (and desirable) source of foreign labor, as it is expected to produce bilingual and bicultural foreign workers with much needed skills and credentials specific to the local labor market (Ziguras and Law, 2006; Suter and Jandl, 2008; Terakura, 2009). Armed with human capital nourished through host education, those foreigners are expected to assimilate smoothly into the host society (Suter and Jandl, 2008; Sakanaka, 2011). In line with this, the newly implemented pointbased immigration policy awards 5 "bonus" points to foreigners with a Japanese educational degree (and 10 additional points to those proficient in Japanese) toward a passing score of 70 (Ministry of Justice, 2012). Educationally channeled migration, therefore, is an "ideal" strategy, particularly for a country, such as Japan, that tries to maintain its national and cultural homogeneity while incorporating foreign talent necessary to boost its global competitiveness (LDP, 2008; Ministry of Education, Culture, Sports and Technology, 2008; Sakanaka, 2011).

How do educationally channeled migrants fare in Japan, in comparison to those without local educational credentials? Although numerous studies have demonstrated that immigrants with host educational credentials enjoy an economic advantage over others (Ferrer and Riddel, 2002; Zheng and Xie, 2004; Krupka, 2007; Fong and Cao, 2009; Arbeit and Warren, 2012), human capital obtained over time in Japan does not 
appear to yield as much economic reward as it is generally expected. We find instead that negative assimilation is largely at work. That is, neither duration in Japan nor the acquisition of Japanese education contribute to higher wages. What contributes to their economic success is rather "foreign capital," or skills directly brought from abroad. A key to economic success in Japan, at least in terms of wages, thus, lies in how best to utilize foreign capital brought from abroad. Subsequently, those in possession of foreign capital and better positioned to put it in practice are more likely than others to earn higher wages in Japan. According to our analysis, the negative assimilation model was found to be more applicable to English-speaking migrants from the West than to Asian migrants, although a premium attached to foreign capital exists regardless of national origins.

Drawing on data collected on the major skilled migrant populations in Japan (Chinese, Koreans, and English-speaking migrants from North America, Western Europe, and Oceania), we demonstrate below how negative assimilation works, as immigrants increasingly become integrated into Japanese society. It is ironic that locally nourished human capital is not always valued in the labor market despite the government's efforts to lure and cultivate foreign talent via local education. This finding helps us understand not only the mechanisms and opportunities of immigrants' social mobility in Japan; it also offers important implications for the effectiveness and consequences of such a policy to attract foreign skills, particularly via education.

Before proceeding to the results of our analysis, we first present a general overview of how immigrants "make it" and how education plays a role, whether it was obtained in the host society or immigrants' countries of origin.

HOW IMMIGRANTS "MAKE IT" IN THE HOST SOCIETY THE ROLE OF EDUCATION

\section{Positive Assimilation}

Immigrants' economic mobility has predominantly been explained by assimilation or what Chiswick and Miller $(2011,2012)$ call "positive assimilation." On average, immigrants earn less than their native-born counterparts, because they often lack directly transferable skills (Ferrer and Riddel, 2002; Borjas, 2006; Portes and Rumbaut, 2006; Haskins, 2008; 
Arbeit and Warren, 2012; Kanas et al., 2012). Moreover, as immigrants tend to originate in poorer countries, the type of skills they bring from home may not be readily applicable to richer countries. With increased duration in the destination, their economic status generally improves, as they assimilate and acquire skills specific to the host society (Chiswick, 1978, 1979; Waldinger and Perlmann, 1998; Alba and Nee, 2003; Akresh, 2006; Portes and Rumbaut, 2006). This "positive assimilation" model, consistent with classic assimilation theory, is so robust, according to Chiswick and Miller (2011), that it has been found for all the major immigrant receiving countries and time periods, tested with various sources of data.

Central to this model is the accumulation of host-country experience. Human capital always has a country-specific component, such as knowledge of local institutions and culture and customs (Ferrer and Riddel, 2002; Portes and Fernandez-Kelly, 2009; Connor and Massey, 2010). Thus, greater experience, or merely more time spent, in the host society usually translates into higher earnings. Accordingly, education acquired in the host society is regarded as a key determinant of immigrants' economic achievement.

\section{The Role of Host versus Foreign Education}

As demonstrated in numerous studies, host society education helps immigrants learn the host language and culture and acquire skills relevant for the local labor market. In their study on immigrants in Germany, Kanas et al. (2012) found that those who obtained their education in the host country had higher occupational status and annual income than those who did not acquire German education. Likewise, Akresh (2006) empirically showed that having some U.S. education improves the occupational status of immigrants in the U.S. According to Lianos, Asteriou, and Agiomirgianakis (2004), graduates from European universities tend to fare better than other degree holders in the Greek labor market.

By the same token, foreign degrees, in general, are worth less than local degrees. Zheng and Xie (2004) specifically showed that U.S. immigrants with foreign degrees earned 14 percent less per year than U.S. degree holders. Li (2001) also found that foreign-educated immigrants in Canada earned about $\$ 10,000$ less than Canadian-educated immigrants annually. This "discount effect" (Fong and Cao, 2009), or penalty associated with foreign education, may be attributed to employers' preference 
or inability to evaluate foreign degrees properly (Arbeit and Warren, 2012); in the eyes of employers, foreign education may impart fewer skills deemed useful. In short, foreign credentials may simply be non-transferable or non-applicable; or else, they may be devalued to protect native workers by minimizing competition from newcomers (Da Vanzo and Morrison, 1981; Fong and Cao, 2009).

The value of foreign education varies, however, depending on where it was obtained. According to Akresh (2007), educational credentials earned in Canada and Western Europe are valued more in the U.S. than those earned in Asia or Latin America (See also Bratsberg and Ragan, 2002). Similarly, Arbeit and Warren (2012) demonstrate that Canadian or U.K. degree holders in the U.S. are more likely than their Latin American or Caribbean counterparts to engage in jobs in the fields in which the degrees were earned. Thus, the discount effect of foreign education may depend on its transferability, reflected in the cultural or linguistic distance between the host and home countries (Chiswick and Miller, 2011, 2012).

\section{Negative Assimilation}

Whereas "positive assimilation" remains a dominant model in explaining immigrants' economic mobility, "negative assimilation" (Chiswick and Miller, 2011, 2012) posits that some immigrants, who come in with readily transferable skills, do not necessarily follow the traditional path of upward economic mobility. That is, earnings decrease with duration in the host society. According to the authors, the model is applicable only to immigrants from developed countries similar in culture, language, and labor market practices to the host society. Those who are already "assimilated" tend to start out high on the economic ladder (or they migrate only when they expect higher wages than at home), and with relatively little additional investment in on-the-job training, their wages tend to decline over time. In the words of the authors, the economic rent that motivated the initial migration declines over time (Chiswick and Miller, 2011, 2012).

There are a number of possible reasons for the decline in the economic rent. First, the demand for immigrants' skills that initiated the migration may not last for long. When immigrants' skills are scarce and badly needed, it is certainly possible to earn high wages without assimilating (Gans, 2007), yet labor market conditions do change over time. Moreover, the type of immigrants' skills needed may require fresh skills brought directly from abroad, thus the value of foreign skills initially 
appreciated may decrease over time as immigrants stay longer in the host society. In Japan, where English skills are highly scarce and valued, for instance, there is a constant demand for native English instructors. As fresh skills from abroad are often preferred for foreign language teaching, this often results in higher remuneration for newer recruits and high rates of job rotation among foreign language teachers in Japan (Yonezawa, Ishida, and Horta, 2013).

A second reason has to do with immigrants' selectivity and motivations. Those immigrants who experience negative assimilation are likely to be a selected group of individuals who were drawn to the destination because of high earnings or higher returns to their skills than expected elsewhere. In other words, they migrated because they expected high initial wages, and not because they expected to accumulate locally specific skills to gradually increase their labor market competitiveness. This may particularly be the case of highly skilled workers, such as foreign expatriates of multinational corporations and IT professionals, who frequently job hop across countries in search of better opportunities (e.g., Beeverstock, 2005; Bauder, 2012).

Moreover, the decline in the economic rent may simply reflect migrants' mobility patterns. Those who come in with globally transferable skills may not stay long in the destination, especially as they see the economic rent decline over time. The owners of globally transferable skills tend to be more mobile and move wherever the returns are highest. This mobility pattern may result in the gradual decrease of average wages by leaving behind those who are less able to expect higher wages elsewhere. ${ }^{3}$ The rising costs of return migration over time may also explain this selection. As immigrants stay longer in the host society, they are likely to form families or establish new personal contacts, making it more difficult to move back or onward. As the costs of return keep rising, immigrants may find decreasing wages more acceptable over time.

In short, negative assimilation suggests that host society experience may not always contribute to upward economic mobility. Unlike the type of immigrants typically assumed in the conventional model of positive assimilation, those immigrants with readily transferable global skills do not necessarily gain economically from assimilation or time spent in the

${ }^{3}$ Chiswick and Miller (2011) do not use panel data, and thus do not follow the same individuals over time, in discussing the relative decline of wages of those who experience negative assimilation. Instead, they use census data taken at different points in time. 
host society. When and where does negative assimilation occur then? More specifically, what kind of immigrant skills are valued, and not valued, and how does it relate to the process of acquiring host-specific skills? We now demonstrate immigrants' social mobility patterns in Japan by comparing the effects of human capital acquired in Japan and abroad.

\section{DATA AND METHODS}

\section{Data}

At present, it is difficult, or nearly impossible, to draw random sampling among foreign residents in Japan due to a lack of large-scale systematic data and of the reliable registration system in place. ${ }^{4}$ The largest dataset available to date is the Census which began to collect information on foreign residents in 1995. Yet, given its limited information and access to micro data, it does not allow us to fully analyze immigrants' socioeconomic integration by taking into account crucial factors such as income, Japanese language proficiency and the year of immigration to Japan (See for instance, Omagari et al., 2011; Korekawa, 2012).

Given these limitations, we conducted a web-monitoring survey for this study. Even though such a method necessarily entails measurement errors and sampling bias (Couper, 2000; Honda, 2007), it is nevertheless the most feasible method to gather large-scale micro data on foreign residents in Japan today. The survey was conducted between the months of February and August 2012 through two research companies that specialized in immigrant communities and had a large list of foreigners registered as their monitors. ${ }^{5}$ Among those monitors, we included in our analysis only "newcomers" who came to Japan after the passage of the new immigration law in 1989 (thus excluding multigenerational long-term Korean residents who became incorporated into Japan under different circumstances). To analyze immigrants' economic incorporation and social

\footnotetext{
${ }^{4}$ The registration system for foreign residents was not well enforced or implemented until the Law of the Basic Resident Registers was passed in July, 2012. Although it is now fully integrated into the national registration system, the government anticipates it will still take long to be able to keep track of all foreign residents. According to a recent press report, many registration forms sent by local governments to foreign residents were returned due to the "unknown" whereabouts of foreign residents.

${ }^{5}$ We made sure that there was no overlap in the sample drawn by the two research companies.
} 
mobility over time, we focused on non-students, aged 16-69, who had resided in Japan for at least three years so as to exclude temporary visitors and residents. Our sample targeted three major immigrant groups who migrated to Japan under the skilled migration policy: (1) Chinese, (2) Koreans, and (3) so-called "Westerners" from five English-speaking countries (U.S., UK, Canada, Australia, and New Zealand). ${ }^{6}$ According to the latest immigration statistics available, these three groups together constituted about 67 percent of all foreign "newcomers", in 2013 (Ministry of Justice, 2014) and roughly 90 percent of skilled foreign laborers ${ }^{8}$ in Japan (Ministry of Health, Labour and Welfare 2013). For the purposes of our analysis, we restricted the sample to residents of the Kanto and Kansai metropolitan areas in order to control for regional differences. ${ }^{9}$ In the end, this yielded a total of 898 immigrants in our sample (200 Chinese, 384 Koreans, and 314 Westerners).

Although the sample is neither representative nor generalizable of the nation's entire foreign population, it nevertheless captures a substantive segment of the population of our interest: the educated and skilled targeted by the Japanese government. "Newcomers" from China, Korea, and the West tend to be highly educated and urban as a whole. According to the Japanese Census (2010), 82 percent of Americans, 37 percent of Chinese, and 31 percent of Koreans ${ }^{10}$ surveyed responded that they graduated from college or graduate school, and over 60 percent of Chinese, 70 percent of Koreans, and 65 percent of Americans were residing in the Kanto and Kansai metropolitan areas (Ministry of Justice, 2014). As urban residents tend to be more educated and engage in professional

\footnotetext{
${ }^{6}$ Although the survey initially included South Americans (Brazilians and Peruvians), we excluded them from our analysis, because most of them did not enter Japan under the skilled migration policy and also because they were underrepresented in the sample.

${ }^{7}$ Excluding long-term Korean residents who hold "special permanent residency."

${ }^{8} \mathrm{~A}$ rough estimate referring to foreign laborers engaged in occupations defined as "skilled" based on visa categories.

${ }^{9}$ These metropolitan areas (Tokyo, Kanagawa, Chiba, Saitama, Osaka, Kyoto, and Hyogo) have the largest number of foreign residents as well as the most diverse nationalities. We did not include the Nagoya area, for example, because its foreign population is dominated by one nationality - Brazilian.

${ }^{10}$ These figures include special permanent residents and other migrants on family-related visas whose levels of educational attainment tend to be lower than work visa holders. Family-related visa holders are more disproportionately represented among Korean and Chinese migrants than Americans.
} 
occupations (Census, 2010), we believe that our sample, though skewed toward an "elite" segment of the population, is sufficiently generalizable to analyze how the kinds of immigrants targeted by the Japanese government fare and achieve economic mobility in Japan.

\section{Models}

To assess whether positive or negative assimilation is more applicable in explaining immigrants' mobility patterns in Japan, our analysis focuses on two key parameters. One is duration in the host society. As explained in the previous section, classic assimilation thesis assumes that duration in the destination is a good proxy for immigrants' knowledge and skills relevant for the host labor market; this should reflect in higher wages. Accordingly, we test if duration in the destination does yield positive effects on wages. The other key parameter is country-specific human capital investments in the destination, also assumed to have a positive impact on wages. Together, the positive effects of both parameters would confirm positive assimilation, while negative coefficients would imply negative assimilation.

These parameters are tested in the following Mincerian-type wage equation where the wage of an individual worker $i$ is a function of years since migration (hereafter, YSM) and skills acquired in the host society (SHS), in combination with other control variables:

$$
\log \left(W_{i}\right)=\alpha+X_{i}^{\prime} * \beta+\gamma * Y S M_{i}+\delta * S H S_{i}+e_{i}
$$

where $\log (W)$ represents the natural logarithm of individual annual earnings being examined, $X$ is the vector of individual characteristics to be controlled for, such as age, years of schooling, and gender, and $e$ is a random disturbance with mean zero and constant variance.

The models are tested in two steps, analyzing the two key parameters in turn. ${ }^{11}$ The first models (Models I-a and I-b) test YSM as the key

\footnotetext{
${ }^{11}$ Past studies, including Chiswick and Miller (2011, 2012), typically analyze immigrants' earnings based on male-only samples (also Chiswick, 1978 and Borjas, 1993). That is because labor market incorporation and income attainment patterns are a gender-specific process. In our analysis, however, we did not separate the sample by gender, partly because of our small sample size, and mostly because there was no significant difference between males and females in the overall negative assimilation pattern. Although males significantly and consistently earned higher wages than females, the determinants of wages, as well as the impact of assimilation and acculturation on wages, was comparable. In future research, however, it is important to explore gender differentials further by using a larger data set.
} 
independent variable. If the coefficient of $Y S M$ is positive and statistically significant, it implies that immigrants' earnings improve with duration in the host country (i.e., positive assimilation). If the coefficient is negatively significant, however, it alludes to negative assimilation; earnings decline with the passage of time in the destination.

Then, host society-specific human capital - education acquired in Japan - is added (Models I-c and I-d) to test its effects on earnings. The positive and statistically significant coefficient of this variable would support previous studies, concluding that locally obtained education help immigrants earn higher wages. If, on the other hand, the coefficient is negative and statistically significant, we would conclude that skills and credentials specific to the Japanese labor market are not as valued as skilled directly brought from abroad.

The next step is to run the same regression models separately for each of the two regions from which immigrants in our sample originated (Models II) - China, Korea, and the English-speaking West (the U.S., the U.K., Canada, Australia, and New Zealand). Following the previous studies, outlined earlier, that found differential effects of foreign degrees, we attempt here to clarify how positive and negative assimilation work, when it occurs, and for whom by assessing the possible effects of regional differences: (1) whether the value of foreign credentials varies by region of origin; (2) whether such value is observed only in a specific region of origin; and (3) whether the overall determinants of earnings differ depending on where immigrants come from.

\section{Variables}

Table 1 summarizes all the variables used for the models. The dependent variable is the natural logarithm of annual wage before tax deductions during the 2011 calendar year. The response category in the original questionnaire ranged from 1 (=no income) through 16 (=more than 15 million Japanese Yen or henceforce, JPY). We set the minimum $(1=$ no income and $2=$ less than 0.5 million JPY) to zero and maximum $(16=$ more than 15 million JPY) to 15 million JPY. Then, the first two categories (zero and under 0.5 million JPY) and the last category (over 15 million JPY) were taken out from the sample (to exclude extreme values), and the median value for categories between $3(=0.5$ million to 0.99 million JPY) and 15 (=10 million to 14.99 million JPY) was used for our analysis. 


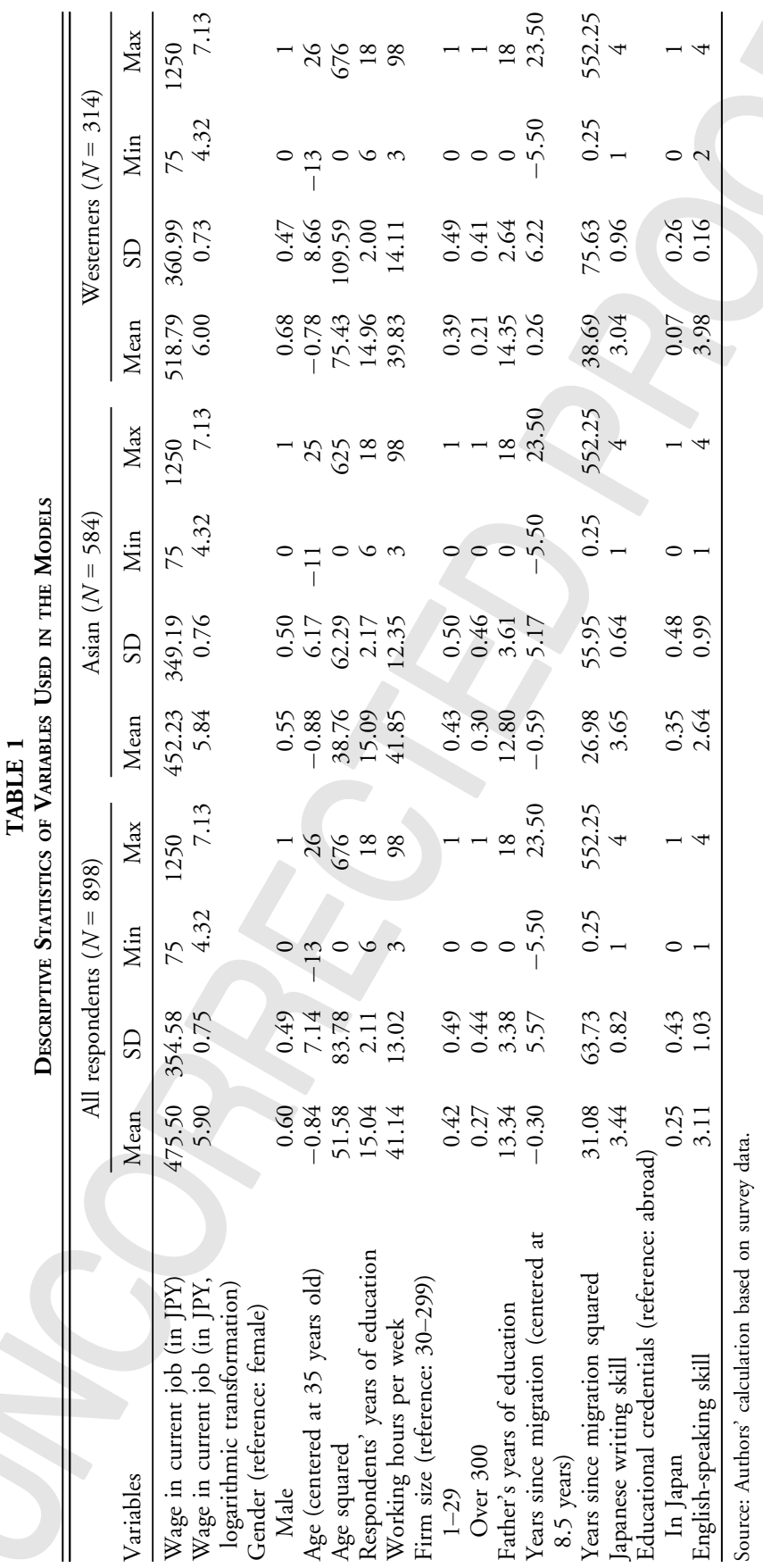


One of the key independent variables, YSM (Year Since Migration), refers to the length of time in Japan, measured as the number of years since first arrival in Japan. Another key independent variable, the place in which the highest degree was earned, is based on the question of whether the degree was earned in Japan, country of birth, or a third country. As relatively few earned their degrees in a third country, we combined the latter two as foreign degrees as opposed to degrees earned in Japan. This variable is intended to measure the type of human capital, whether it was invested and acquired pre-migration abroad or post-migration in the host society.

Other independent variables include education, expressed as years of schooling acquired in any country, and additional factors deemed to affect earnings, such as father's education, ${ }^{12}$ gender, working hours per week, firm size, Japanese proficiency, and English proficiency. Father's education is used as a measure of one's socioeconomic background. Numerous studies have found that father's socioeconomic status is strongly related to one's economic attainment, either directly or indirectly (e.g., Tachibanaki, 1988). ${ }^{13}$ Gender, the number of work hours, and firm size have also been identified as crucial determinants of earnings, particularly in Japan; males generally earn more than females, net of other factors, as do employees of larger firms and individuals who put in more hours at work (e.g., Sano and Yasui, 2009; Statistics Bureau of Japan, 2012). Japanese proficiency is measured on a 4 -point scale $(1=$ little; 2 = not so good; 3 = average; $4=$ good) based on the subjective evaluation of respondents' writing abilities. English proficiency, measured similarly on a 4-scale point, is also added to our models, as it has frequently been identified as a crucial skill valued in the Japanese labor market (See, for instance, Watanabe, 2003). ${ }^{14}$

\footnotetext{
${ }^{12}$ Father's education is treated here as a continuous variable, measured as years of schooling, because in most cases, respondents' fathers completed their education outside of Japan.

${ }^{13}$ Some researchers, including Tachibanaki (1988), confirm that father's education (used as a proxy for parental socioeconomic status) directly affects children's economic outcomes, while others, such as Sano and Yasui (2009), suggest that father's education affects children's economic outcomes only indirectly through children's education or the standard of living at home.

${ }^{14}$ It is to be noted that age and $Y S M$ are centered at mean to avoid possible multicollineality problems. In analyzing the effects of $Y S M$, we subtracted its mean (8.5 years) from each value; similarly for age, the mean of 35 was subtracted from each value.
} 
The descriptive statistics summarized in Table 1 show that the average immigrant in our sample is 35 years old with a foreign college degree and has lived in Japan for 8.5 years; currently, s/he engages in full-time employment, working $8 \mathrm{~h}$ a day at a medium or large-sized firm. The average annual wage of 4.75 million JPY is significantly higher than the national average, 4.12 million JPY, among all employees in Japan in 2010 (National Tax Agency, 2012).

Table 1 also shows a substantial difference in earnings between immigrants from Asia and the English-speaking Western countries included in our analysis. The average immigrant from the West earns 5.18 million JPY annually, over 0.5 million JPY more than the average Asian (4.52 million JPY). Westerners earned more than Asians, on average, even though there were no significant differences in age, education, and years since migration, and despite their lower level of Japanese proficiency (a score of 3.04 as opposed to 3.65 for Asians) and lower likelihood to earn their degrees in Japan ( $7 \%$ compared with $35 \%$ for Asians).

\section{RESULTS}

\section{Baseline Model (Models I- $a$ and I-b)}

Our analysis begins with a baseline model (Models I-a and I-b in Table 2), based on the entire sample, to assess the applicability of the assimilation model, either positive or negative. The coefficients estimated by ordinary least squares (OLS) are reported in Table 2, along with the heteroskedasticity-robust standard errors. Model I-a includes only a linear variable for $Y S M$, and quadratic $Y S M$ is added in Model I-b. Overall, the coefficients of the variables included in the models are mostly significant in predicted directions. Being male increases wages, as does the higher level of parental socioeconomic status. One also earns more by working longer hours and at a larger firm. The return to education, regardless of where the highest degree was earned, is positive at the 5 percent significance level.

The most remarkable finding here is the negative effect of YSM; while the coefficient is insignificant in Model I-a, it turns significant, once quadratic $Y S M$ is added (Model I-b). This suggests that YSM has a Ushape, rather than a straight-line, effect on wages. Specifically, it negatively affects wages for the first 13 years, but thereafter, its effect turns positive. That is, the negative assimilation pattern is observed for the first 13 years 


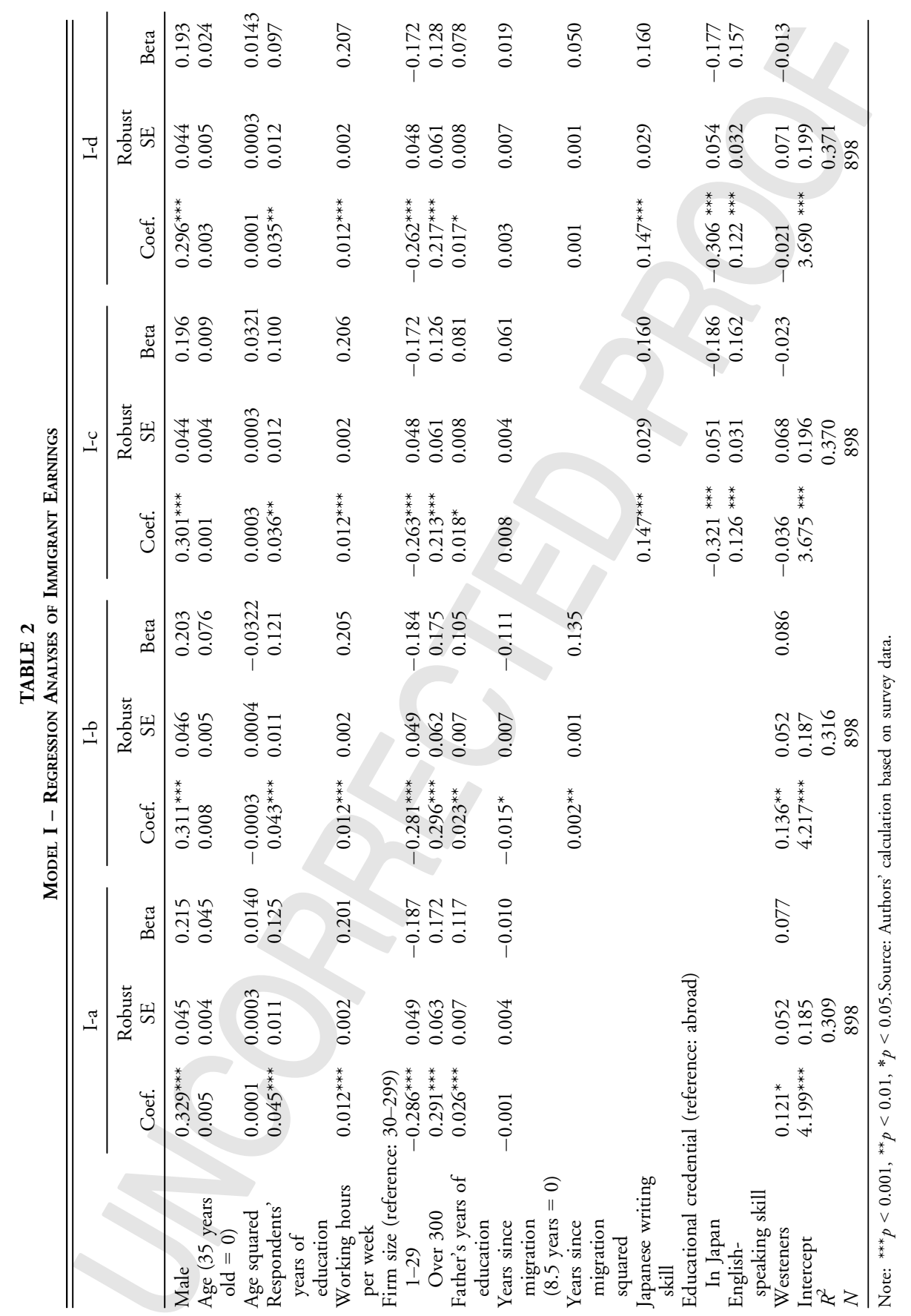


in Japan, or it takes 13 years before the positive effect kicks in. Negative assimilation is prevalent in Japan, given that most foreigners stay less than 13 years in the country (Ministry of Justice, 2014). And this trend is robust, regardless of the recession that has plagued the country over the past decades. Although the nation's average wage has decreased due to the recession, this does not seem to have driven immigrants' wages downward in the same way. ${ }^{15}$ Therefore, contrary to Western countries where immigrants typically experience positive assimilation, immigrants in Japan, at least the skilled and educated targeted by the government, appear to undergo a different process of economic assimilation. ${ }^{16}$

\section{Extended Model with Country-Specific Human Capital (Models I-c and $I-d)$}

To further explore the role of location-specific human capital, the next step is to test the effect of the place where the highest degree was obtained. It is measured as a dummy variable coded as 1 if the degree was completed in Japan and 0 if otherwise. The results of Models I-c and I-d (See Table 2) show that the coefficient of this variable is negative and statistically significant at the 0.1 percent level, suggesting that education acquired in Japan is negatively related to immigrants' wages. What it implies on the flip side is that skills brought from abroad contribute more to higher wages in Japan. Judging from the standardized coefficient of this variable, the magnitude of its effect is quite large relative to other independent variables, including years of schooling. This indeed suggests that the type of education (whether education is attained in the host society or abroad) may matter more than the overall level of education (general human capital) in predicting immigrant earnings in Japan.

Models I-c and I-d also test the effects of Japanese and English writing skills on wages. Both positive and significant, the results are consistent

\footnotetext{
${ }^{15}$ While the prolonged recession has resulted in lowering the average wage in Japan, it has not affected the wages of the skilled and educated employed by larger firms as much (Ministry of Health, Labour and Welfare, 2012). Among our sample, we consistently observed negative (and non-positive) assimilation trends, even after controlling for firm size, job tenure, and various skill levels of individuals.

${ }^{16}$ The inclusion of many independent variables in the models could potentially cause multicolinearity. However, we confirmed that there is no evidence of severe colinearity among the independent variables according to the Variance Inflation Factors (VIF) we computed.
} 
with previous studies (e.g., Alba and Nee, 2003; Portes and Rumbaut, 2006). As shown by its strong positive coefficient, English proficiency, as a type of capital brought from abroad, is highly valued in the Japanese labor market. Japanese proficiency, a crucial host society-specific human capital, is also confirmed vital to economic success. Yet, what is surprising is that Japanese proficiency is not correlated with YSM. Thus, the Japanese skills valued here are not a product of experience accumulated in Japan; rather, they reflect skills acquired abroad. Foreign capital, or skills brought from abroad, once again, proves to be a crucial determinant of immigrants' economic success in Japan. Thus, immigrants in Japan do not quite seem to follow the positive assimilation path prevalent in Western countries.

\section{Mechanisms of Negative and Non-Positive Assimilation}

Taken together, time spent in Japan largely has either a negative or nonpositive (insignificant) effect on earnings. Moreover, human capital accumulated in the host society, measured as education attained in Japan, has a robust negative effect on immigrant wages. Why does host-specific human capital matter less than foreign capital brought from abroad? This may, in part, be explained by what immigrants actually do with their skills in Japan.

Figure 1 shows that there is a substantial difference in occupational status between immigrants with foreign and Japanese educational credentials. Those who earned their highest degrees abroad are more likely to engage in professional, technical, or managerial jobs $(71.7 \%)$ than others with Japanese educational credentials $(51.4 \%)$. A majority of foreign-educated immigrants in our survey engaged in teaching, language editing, trade, and IT - the types of jobs that are likely to complement skills possessed by natives - in Japan. On the other hand, immigrants educated in Japan tended to take up jobs that would face more direct competition with natives, such as clerical jobs, sales, or general managerial work in companies. According to a survey conducted by JASSO (2005) among foreign graduates from Japanese universities, a majority of those who stayed in Japan were company employees engaged in translation/interpretation business $(28 \%)$, technical development (11\%), or operations and sales $(11 \%)$ - in short, they mostly engaged in general office work, like natives, within a Japanese company setting. Unlike the findings of previous research for other countries introduced earlier, foreign credentials were 
Figure 1.

Occupational Status by Location in Which the Highest Degree Was Earned

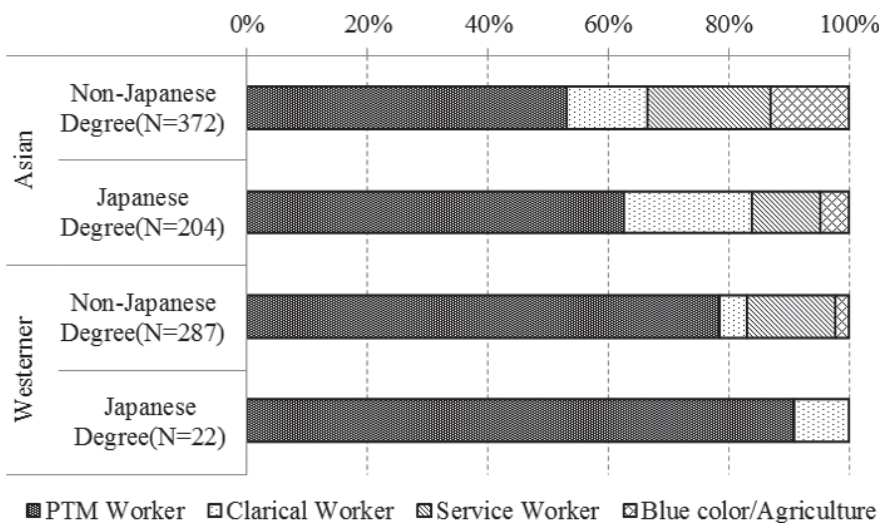

Note: PTM represents professional, technical, and managerial types of occupations. Non-PTM represents clerical and manual type of occupations.

Source: Authors' Calculation Based on Survey Data.

likely to lead to more highly remunerated professional jobs in Japan, because they were often channeled into a different sector of the labor market (specific types of jobs) where such skills are regarded a premium not possessed by natives.

To further test whether there were significant differences in backgrounds between migrants educated in Japan and elsewhere, we ran a simple correlation between the place of the highest degree and a select number of observable characteristics, such as father's education, gender, and age (Table 3). The weak or insignificant correlations suggest that the place of the highest degree is more or less randomly distributed. The reason foreign capital matters, therefore, does not seem to hinge on migrants' selectivity; the degree earned in Japan or abroad has an independent effect on wages in Japan.

A better clue as to why foreign education matters may lie in what is actually valued in the Japanese labor market. Namely, the kind of foreign capital valued may have a specific regional or cultural component. As discussed earlier, Chiswick and Miller $(2011,2012)$ stipulate that negative assimilation occurs only when immigrants with perfectly transferable skills (e.g., native English fluency) move from countries with comparable levels of economic development. In line with this, negative assimilation observed in Japan may be more applicable to highly skilled immigrants from highincome countries. Stated differently, the type of foreign skills valued in 
TABLE 3

Correlation between Japanese Degree Holders and their Family and Demographic CharacterisTICS

\begin{tabular}{ll}
\hline \hline & Corr. Coef \\
\hline Male & $-0.14^{* * *}$ \\
Age $(35=0)$ & $-0.09^{*}$ \\
Father's years of education & -0.02 \\
\hline Note: ${ }^{* * *} p<0.001, * * p<0.01, p<0.05,{ }^{\dagger} p<0.1 ; N=898$ Source: Authors' calculation based on survey data
\end{tabular}

the Japanese labor market may be regionally or culturally specific. To test this, we now examine the results of separate regression analysis for Asia (China and Korea) and the English-speaking "West" (the U.S., the U.K., Canada, Australia, and New Zealand).

Separate Models by Region and Country (Models II-a, II-b, II-c, and II-d)

The results summarized in Table 4 show some regional differences. Negative assimilation is strongly at work for Westerners, and this applies only to Westerners. ${ }^{17}$ For Asians, the coefficients of $Y S M$ and quadratic YSM do suggest negative assimilation in Model II-a, but their effects disappear once the foreign capital variables are included (Model II-b). This suggests that their wages are explained more by foreign degrees and English skills than by the duration of time in Japan. Moreover, Asian migrants appear to gain economically by working for long hours at larger firms, a pattern similar to native Japanese workers (e.g., Sano and Yasui, 2009).

For Westerns, the negative effects of YSM remain robust, even after controlling for foreign capital (Models II-c and II-d). Unlike migrants from Asia and native Japanese workers, moreover, Westerners do not earn significantly more by working at larger firms. Nor do longer work hours contribute as much to their wages as to their Asian counterparts. For migrants from the West, therefore, negative assimilation is clearly at work in Japan.

For both groups, education attained in Japan has a negative effect, while English skills (for Asian) have a positive effect on wages. Thus, a premium attached to foreign capital remains strong regardless of where

${ }^{17}$ It is to be noted here, again, that the computed VIF suggests no severe colinearity among the independent variables included in Models II-a and II-b. 


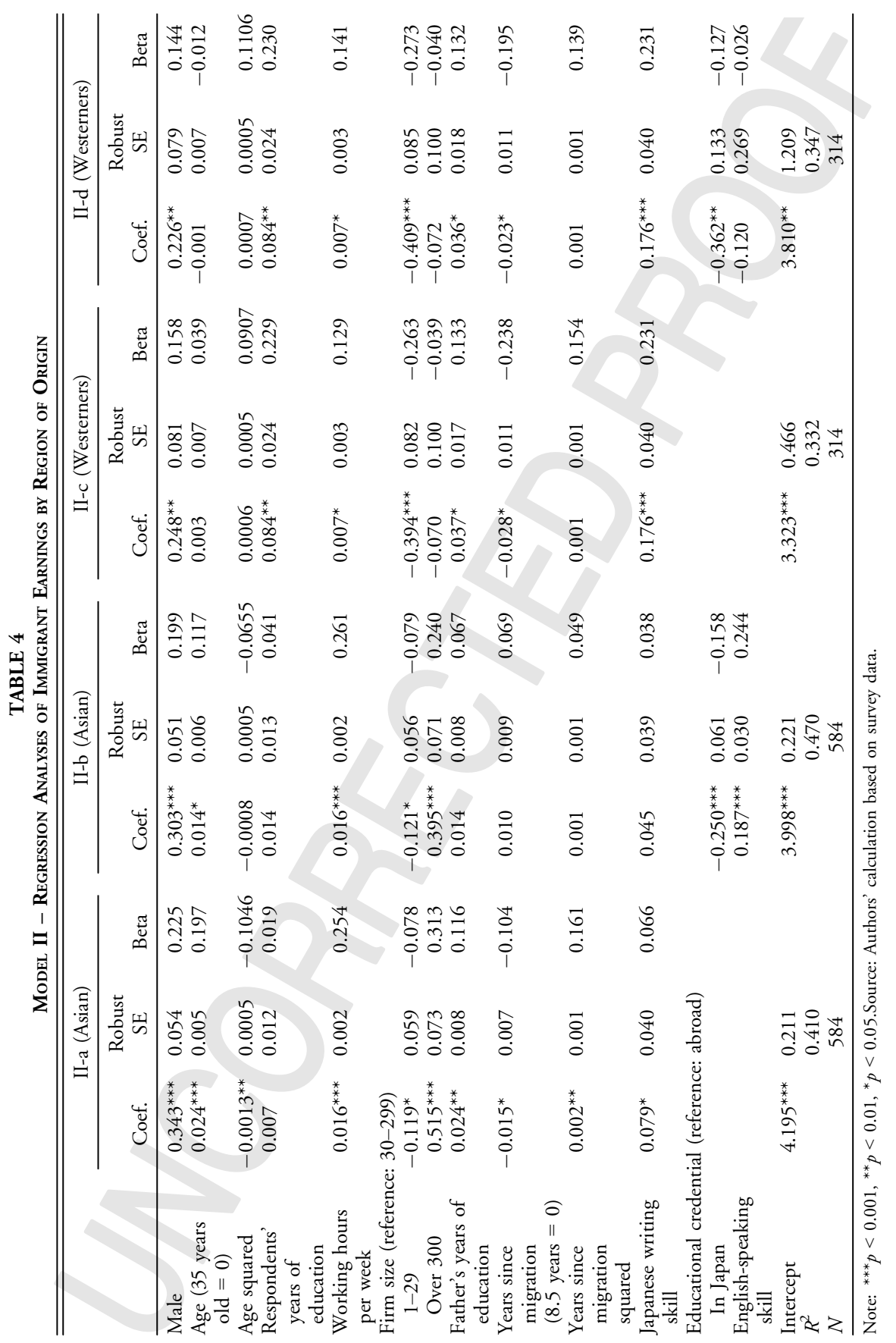


migrants come from. This may be due to the relatively short supply of personnel sufficiently proficient in English or other foreign skills in Japan, as reflected in the small number of Japanese who study abroad or earn a degree abroad (See Institute of International Education, 2012; JASSO, 2012). It may also reflect the Japanese immigration policy that accords premiums to foreign skills brought from abroad.

The regression analysis performed separately by region shows that a different mechanism may be at work in explaining the economic mobility of each geographical group. As mentioned earlier, Asian migrants, particularly those educated in Japan, may follow (or are expected to follow) the economic mobility path typically experienced by natives - obtaining employment in larger prestigious firms by going through specific labor recruitment practices learned in local educational institutions. While they reap economic rewards by following the path, the foreign capital they possess still has a labor market premium. And this is robust and consistent, regardless of their job tenure and employment status, as well as how long they stay in Japan.

The different results observed between the two regional patterns may imply that foreign capital brought from the West, such as English skills, are particularly valued in the Japanese labor market. Alternatively, Westerners, who are less likely than Asians to possess Japan-specific human capital, such as Japanese language proficiency and local education, may be more predisposed to utilize their foreign capital in the Japanese labor market. Westerners may also be expected to follow an economic mobility path distinct from Japanese natives. This may be akin to Westerners brought into Japan as government advisors ("oyatoi gaikokujin") who assumed separate, yet economically superior, positions during the Meiji period (1868-1912) of Japan's modernization (e.g., Jansen, 2000). The pattern observed here may also be comparable to the case of Kikokushijo, or privileged Japanese returnees from abroad studied by Goodman (1990), in that those who bring special skills from abroad, especially from the West, may be preferentially incorporated into Japanese society. Today, when "global skills" are highly sought, educated foreign migrants with skills deemed useful may indeed have an advantage over natives without such skills.

In sum, the positive assimilation thesis commonly used to explain immigrant economic mobility in the West does not seem to apply in the same way to Japan. While foreign skills directly brought from abroad contribute to higher wages, human capital accumulated in the host society seems to put immigrants at relatively disadvantaged positions. 


\section{DISCUSSION AND CONCLUSIONS}

In the context of growing competition for global talent, educationally channeled migration is increasingly seen and identified as an important national strategy in Japan (Terakura, 2009). It is a strategy to smoothly integrate immigrants into Japanese society, while tapping into foreign talent to reinvigorate Japan's economy ("New Growth Strategy" cited on P. 3). This strategy is fundamentally rooted in the widespread belief in positive assimilation that locally acquired capital fosters immigrants' assimilation and hence upward economic mobility. It is indeed in accordance with many past studies, as mentioned earlier, demonstrating the "value" of host education in explaining immigrants' economic attainment.

Given our findings, however, the Japanese policy strategy may end up producing immigrants who are unable to gain economic rewards commensurate with their skill levels. Without economic rewards, the value of Japanese education may diminish, particularly for the highly skilled who can expect higher economic rewards elsewhere. The most talented and able with globally transferable skills may simply opt to move elsewhere, using Japan as a stepping-stone or altogether bypassing the country. The current strategy to lure skilled immigration via education may, therefore, reinforce the sorting mechanism of immigration, not only of who comes to Japan in the first place, but also of who stays and who moves on from Japan.

More generally, our findings also suggest that assimilation via host education does not always lead to immigrants' upward economic mobility. Although the extent to which immigrants achieve parity with natives is often assumed as a key indicator of immigrants' economic success (e.g., Constant and Zimmermman, 2009; Borjas, 2013), assimilation, or becoming similar to natives, is not always desirable, or certainly not the only strategy, to attain economic mobility. As we have demonstrated, utilizing foreign skills, rather than accumulating skills similar to natives, can also be a strategy for immigrants to move up the socioeconomic ladder. This may particularly be the case for skilled migrants increasingly sought after by many countries.

As more countries, including non-Western and non-traditional countries of immigration, try to compete for skilled migrants, especially via education, we may increasingly witness similar patterns of negative assimilation around the world. The positive assimilation model that has been so dominant, and even assumed, in much of the immigration literature may 
actually be confined to a select number of cases where immigrants with relatively limited skills move from poorer countries to richer (and Western) countries. As Gans (2007) pointed out, we need to interrogate the relationship between assimilation and economic mobility further. This task is particularly vital today, as the types of migration, as well as immigrant destinations and origins, are increasingly becoming diverse, and are expected to become more diverse in the future.

\section{REFERENCES}

Akresh, I. R.

2006 "Occupational Mobility among Legal Immigrants to the U.S." International Migration Review 40(4):854-884.

2007 "US Immigrants Labor Market Adjustment: Additional Human Capital Investment and Earnings Growth.” Demography 44:865-881.

Alba, R., and V. Nee

2003 Remaking the American Mainstream: Assimilation and Contemporary Immigration. Cambridge, MA: Harvard University Press.

Arbeit, C. A., and J. R. Warren (

2012 ). "Labor Market Penalties for Foreign Degrees among College Educated Immigrants." mimeo.

Bauder, $\mathrm{H}$.

2012 "The International Mobility of Academics: A Labour Market Perspective." International Migration. Online version.

Beeverstock, J. V.

2005 "Transnational Elites in the City: British Highly-Skilled Inter-Company Transferees in New York City's Financial District." Journal of Ethnic and Migration Studies 31 (2):245-268.

Borjas, G. J.

1993 "The Intergenerational Mobility of Immigrants." Journal of Labor Economics 11:113-135.

2006 "Making it in America: Social Mobility in the Immigrant Population." The Future of Children 16:55-71.

2013 "The Slowdown in the Economic Assimilation of Immigrants: Aging and Cohort Effects Revisited Again.” NBER Working Paper No. 19116. NBER: ?????.

Bratsberg, B., and J. F. J. Ragan

2002 "The Impact of Host Country Schooling on Earnings: A Study of Male Immigrants in the United States." The Journal of Human Resources 37:63-105.

Census

2010 The Statistics Bureau and the Director-General for Policy Planning of Japan (2010). 2010 Population Census. <http://www.stat.go.jp/data/kokusei/2010/special/ english/index.htm>. Accessed on November 29th, 2012.

Chiswick, B. R. 
1978 "The Effect of Americanization on the Earnings of Foreign Born Men." Journal of Political Economy 86:897-922.

1979 "The Economic Progress of Immigrants: Some Apparently Universal Patterns." In Contemporary Economic Problems. Ed. W. Fellner. Washington, DC: American Enterprise Institute. Pp. 357-399.

2011 "The 'Negative' Assimilation of Immigrants: A Special Case." Industrial and Labor Relations Review 64:502-525.

2012 "Negative and Positive Assimilation, Skill Transferability and Linguistic Distance." Journal of Human Capital 6:35-55.

Connor, P., and D. S. Massey

2010 "Economic Outcomes among Latino Migrants to Spain and the United States: Differences by Source Region and Legal Status." International Migration Review 44:802-829.

Constant, A. F., and K. Zimmermman

2009 ."Migration, Ethnicity, and Economic Integration.” IZA DP No. 4620.

Council on Promotion of Human Resource for Globalization Development

2011 An interim Report of the Council on Promotion of Human Resource for Globalization Development. <http://www.kantei.go.jp/jp/singi/global/1206011interim_report.pdf>. Accessed on August 20, 2011.

Couper, M. P.

2000 "Web Surveys: A Review of Issues and Approaches." Opinion Quarterly 64:464495.

Da Vanzo, J. S., and P. A. Morrison

1981 "Return and Other Sequences of Migration in the United States." Demography 18:85-101.

Ferrer, A. M., and W. C. Riddel

2002 "The Role of Credentials in the Canadian Labour Market." Canadian Journal of Economics 35:879-905.

Fong, E., and X. Cao

2009 "Effects of Foreign Education on Immigrant Earnings." Canadian Studies in Population 36:87-110.

Gans, $\mathrm{H}$.

2007 "Acculturation, Assimilation, Mobility." Racial and Ethnic Studies 30:152-164.

Goodman, R.

1990 Japan's 'International Youth': The Emergence of a New Class of School Children. Oxford: Clarendon Press.

Haskins, R.

2008 "Immigration: Wages, Education, and Mobility." In Getting Ahead or Losing Ground: Economic Mobility in America. Ed. J. Isaacs, I. V. Sawhill, and R. Haskins.

Honda, N. DC: The Brookings Institution, Pp. 81-90.

2007 "Intanetto chousa monita chousa no tokushitsu - monitagata intanetto chousa no katsuyou to kadai- [The Characteristics of the Internet Based Monitor Survey The Applications and Challenge of the Internet Based Monitor Survey]." Nihon roudou kenkyuu zasshi 551:32-41. 
Institute of International Education

2012 Open Doors Data. <http://www.iie.org/en/Research-and-Publications/Open-Doors/ Data/International-Students/By-Academic-Level-and-Place-of-Origin/2010-11>.

Accessed on August 20, 2012.

Jansen, M. B.

2000 The Making of Modern Japan. Cambridge: Harvard University Press.

JASSO (Japan Student Services Organization)

2005 "Shihi gaikokujin ryuugakusei seikatsu jittaichousa." [The survey of current living condition of foreign students at their own expenses]. <http://www.jasso.go.jp/scholarship/ryujchosa17.html>. Accessed on November 29, 2012.

2012 Statistics on Foreign Students in Japan. <http://www.jasso.go.jp/index_e.html>. Accessed on August 15, 2012.

Kajita, T. and T. Miyajima (eds)

2002 ,Kokusaika suru Nihon Shakai [Internationalization of Japanese Society]. Tokyo: University of Tokyo Press. Pp. 15-43.

- , K. Tannno, and N. Higuchi

2005 Kaono Mienai Teijuuka [Invisible Residents: Japanese Brazilians vis-à-vis the State, the Market and the Immigrant Network]. Nagoya: University of Nagoya Press.

Kanas, A., B. R. Chiswick, T. van der Lippe and F. van Tubergen

2012 "Social Contacts and the Economic Performance of Immigrants: A Panel Study of Immigrants in Germany." International Migration Review 46:680-709.

Korekawa, Y.

2012 "Nihon niokeru gaikokujin no teijuka nituiteno shakaikaisouron niyoru bunseki shokugyou tasseito sedaikan idouni shouten wo atete [An analysis of Japan's immigrant settlement process: social stratification, occupational attainment and intergenerational mobility]." ESRI Discussion Paper series, 283. ??????, ??????.

Krupka, D. J.

2007 "Location-Specific Human Capital, Location Choice and Amenity Demand." Journal of Regional Science 49:833-854.

LDP (Liberal Democratic Party)

2008 Jinzai kaikoku nihongata imin seisaku no teigen [Opening up the country: toward a Japanese-style immigration policy]. <http://www.kouenkai.org/ist/pdff/iminseisaku080612.pdf>. Accessed on August 22, 2012.

Li, P. S.

2001 "The Market Worth of Immigrants' Educational Credentials." Canadian Public Policy 27:23-38.

Lianos, T. P., D. Asteriou, and G. M. Agiomirgianakis

2004 "Foreign University Graduates in the Greek Labour Market: Employment, Salaries and Overeducation." International Journal of Finance and Economics 9:151-164.

Liu-Farrer, G.

2009 "Educationally Channeled International Labor Mobility: Contemporary Student Migration from China to Japan.” International Migration Review 43:178-204.

Massey, D., and M. Sanchez

2012 Brokered Boundaries: Creating Immigrant Identity in Anti-Immigrant Times. New York: Russell Sage Foundation.

Ministry of Economy, Trade, and Industry

2007 Plan to Accept 300,000 Foreign Students. <http://www.rjcnetwork.org/wp-content/ uploads/2010/05/g30_plan.pdf $>$. Accessed on August 22, 2012. 
Ministry of Education, Culture, Sports and Technology

2008 Career Development Program for Foreign Students in Japan. <http://www.ajinzai-sc.jp/ index_e.html>. Accessed on August 22, 2012.

Ministry of Health, Labour and Welfare

2012 Chingin Kozo Kihon Tokei Chosa [Basic Survey on Wages]. <http://www.mhlw.go. jp/toukei/itiran/roudou/chingin/kouzou/detail/>. Accessed on July 20, 2013.

Ministry of Health, Labour and Welfare

2014 Gaikokujin koyo jokyo no todokede jokyohyo ichiran [Summary of the Situation of Foreign Laborers]. <http://www.mhlw.go.jp/file/04-Houdouhappyou-11655000Shokugyouanteikyokuhakenyukiroudoutaisakubu-Gaikokujinkoyoutaisakuka/ 0000036118.pdf>. Accessed on February 25, 2014.

2009 "Ryugakuseitou no nihon kigyoutou he no shushoku [Foreign Student Employment to Japanese Firms].” Kokusai Jinryu 9:40-47.

Ministry of Justice

2012 Kodo jinzai ni taisuru pointosei ni yoru yugu seido no dounyu nitsuite [Introducing a Points-Based System for Skilled Foreign Migrants]. <http://www.immi-moj.go.jp/ info/120416_01.html>. Accessed on August 18, 2012.

2014 Toroku gaikokujin tokei [Statistics on Foreign Migrants in Japan]. <http://www. immi-moj.go.jp/toukei/>. Accessed on February 20, 2014; <http://www.immi-moj. go.jp/info/120416_01.html>. Accessed on August 18, 2012.

National Tax Agency

2012 Minkan kyuyo no jittaichousa [The Status Survey of Compensations in the Private Sector]. <http://www.nta.go.jp/kohyo/tokei/kokuzeicho/minkan2011/minkan.htm>. Accessed on November 29th, 2012.

Omagari, Y. et al.

2011 "Gaikokujin no shigoto [Foreign Migrants' Jobs]." Ibaraki daigaku chiiki sogo kenkyujo nenpo [Iraragi University Regional Studies Journal] 44:27-42.

Portes, A., and P. Fernandez-Kelly

2009 Exceptional Outcomes: Achievement in Education and Employment among Children of Immigrants. CA: Sage Publications Inc.

- and R. G. Rumbaut

2006 Immigrant America: A Portrait. LA: University of California Press.

Rumbaut, R. G.

1997 "Assimilation and Its Discontents: Between Rhetoric and Reality." International Migration Review 31(4):923-960.

Sakanaka, H.

2011 Nihongata Imin Kokka he no Michi [Toward a Japanese-style immigrant nation]. Tokyo: Toshindo.

Sano, S., and S. Yasui

2009 "Nihon ni okeru kyouiku no rita-n no suikei [Estimating the Rate of Return to Education in Japan]." Kokumin Keizai Zasshi 200:71-86.

Statistics Bureau of Japan

2012 Economic and Financial Data of Japan. <http://www.stat.go.jp/english/data/index. htm>. Accessed on Retrieved November 29, 2012.

Suter, B., and M. Jandl

2008 "Train and Retain: National and Regional Policies to Promote the Settlement of Foreign Graduates in Knowledge Economies." Journal of International Migration and Integration 9:401-418. 
Tachibanaki, T.

1988 "Education, Occupation, Hierarchy and Earnings." Economics of Education Review 7:221-229.

Takenoshita, $\mathrm{H}$.

2006 "The Differential Incorporation into Japanese Labor Market: A Comparative Study of Japanese Brazilians and Professional Chinese." The Japanese Journal of Population 4:56-77.

Terakura, K.

2009 "Ryugakusei ukeire no igi shogaikoku no doko to waga kuni he no shisa [The Significance of Accepting Foreign Students: Trends in Foreign Countries and Implications for Japan].” Reference 3:51-72.

Tsukazaki, H.

2008 Gaikokujin senmonshoku gijutsushoku no koyo mondai [The problems and conditions of skilled migrant workers]. Tokyo: Akashi Shoten.

Waldinger, R., and J. Perlmann

1998 "Second Generations: Past, Present, Future." Journal of Ethnic and Migration Studies 24:5-24.

Watanabe, $T$.

2003 "Ryugaku keiken to kyaria keisei nihonjin no gaikoku daigaku sotsusha wo rei toshite [Foreign Experience and Career Formation: Japanese Who Graduated From Foreign Universities].” Bulletin of Ohkagakuen University Faculty of Humanities 5:95112.

Yonezawa, A., K. Ishida, and H. Horta

2013 "The Long-Term Internationalization of Higher Education in Japan: A Survey of Non-Japanese Faculty Members in Japanese Universities." In Internationalization of Higher Education in East Asia: Trends of Student Mobility and Impact on Education Governance. Ed. K. H. Mok, and K. M. Yu. London: Routledge, Pp. 179-191.

Zheng, Z., and Y. Xie

2004 “Asian Americans' Earnings Disadvantage Reexamined: The Role of Place in Education." American Journal of Sociology 109:1057-1108.

Ziguras, C., and S. F. Law

2006 "Recruiting International Students as Skilled Migrants: The Global 'Skills Race' as Viewed from Australia and Malaysia." Globalisation, Societies and Education 4:5976. 


\section{Author Query Form}

Journal:

Article:
IMRE

12129

\section{Dear Author,}

During the copy-editing of your paper, the following queries arose. Please respond to these by marking up your proofs with the necessary changes/additions. Please write your answers on the query sheet if there is insufficient space on the page proofs. Please write clearly and follow the conventions shown on the attached corrections sheet. If returning the proof by fax do not write too close to the paper's edge. Please remember that illegible mark-ups may delay publication.

Many thanks for your assistance.

\begin{tabular}{|c|c|c|}
\hline Query reference & Query & Remarks \\
\hline 1 & $\begin{array}{l}\text { AUTHOR: Article title and Abstract } \\
\text { are extracted from the supplied PDF } \\
\text { source file. Please check. }\end{array}$ & \\
\hline 2 & $\begin{array}{l}\text { AUTHOR: A running head short title } \\
\text { was not supplied; please check if this } \\
\text { one is suitable and, if not, please } \\
\text { supply a short title of up to } 40 \\
\text { characters that can be used instead. }\end{array}$ & \\
\hline 3 & $\begin{array}{l}\text { AUTHOR: Authors and affiliations } \\
\text { have been retrieved from "Metadata. } \\
\text { xml" file, please check. }\end{array}$ & \\
\hline 4 & $\begin{array}{l}\text { AUTHOR: Ministry of Health, Labour } \\
\text { and Welfare } 2013 \text { has not been } \\
\text { included in the Reference List, please } \\
\text { supply full publication details. }\end{array}$ & \\
\hline 5 & $\begin{array}{l}\text { AUTHOR: Tables } 3 \text { and } 4 \text { have been } \\
\text { interchanged. Similar changes are } \\
\text { made in text also. Please check. }\end{array}$ & \\
\hline
\end{tabular}




\begin{tabular}{|l|l|}
\hline 6 & $\begin{array}{l}\text { AUTHOR: Please provide the } \\
\text { publisherLoc for reference Borjas } \\
(2013) .\end{array}$ \\
\hline 7 & $\begin{array}{l}\text { AUTHOR: Please check all website } \\
\text { addresses and confirm that they are } \\
\text { correct. Please note that it the } \\
\text { responsibility of the author(s) to } \\
\text { ensure that all URLs given in this } \\
\text { article are correct and useable.) }\end{array}$ \\
\hline 8 & $\begin{array}{l}\text { AUTHOR: Please provide the city } \\
\text { name for "The Brookings Institution, } \\
\text { DC." }\end{array}$ \\
\hline 10 & $\begin{array}{l}\text { AUTHOR: Please provide the } \\
\text { publisherName, publisherLoc for } \\
\text { reference Korekawa (2012). }\end{array}$ \\
\hline 11 & $\begin{array}{l}\text { AUTHOR: Please provide the city } \\
\text { name for "Sage Publications Inc, CA." }\end{array}$ \\
\hline 12 & $\begin{array}{l}\text { AUTHOR: Please provide the city } \\
\text { name for "University of California } \\
\text { Press, LA." }\end{array}$ \\
\hline $\begin{array}{l}\text { AUTHOR: Figure 1 has been saved at } \\
\text { a low resolution of 202 dpi. Please } \\
\text { resupply at 600 dpi. Check required } \\
\text { artwork specifications at http:// } \\
\text { authorservices.wiley.com/bauthor/ } \\
\text { illustration.asp }\end{array}$ \\
\hline
\end{tabular}

